\title{
QUE VEN LOS CONSUMIDORES DETRÁS DE LA RESPONSABILIDAD SOCIAL EMPRESARIA
}

WATCHING THE CONSUMERS BACK OF LIABILITY CORPORATE SOCIAL

ENRIQUE CARLOS BIANCHI GASPAR GRACIA DAPONTE

FACULTAD DE CIENCIAS ECONÓMICAS Y ADMINISTRACIÓN UNIVERSIDAD CATÓLICA DE CÓRDOBA

ARGENTINA.

Hay un tiempo en el que es preciso abandonar las ropas usadas que ya tienen la forma de nuestro cuerpo, y olvidar nuestros caminos que nos llevan siempre a los mismos lugares. Es el tiempo de la travesía: y si no osamos hacerla, quedaremos, para siempre, al margen de nosotros mismos.

Fernando Pessoa. 


\title{
RESUMEN
}

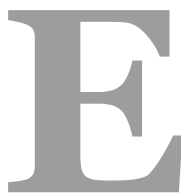

1 presente trabajo tiene por objetivo indagar la percepción emotiva profunda -consciente e inconsciente- de las acciones de Responsabilidad Social Empresaria de diferentes sectores económicos por parte de los consumidores utilizando la técnica cualitativa ZMET (The Zaltman Metaphor ElicitationTechnique), identificando las marcas arquetípicas y su sombras que estigmatizan como conductas "positivas" "negativas" o "ambivalentes", con el fin de crear un marco de análisis para comprender el porqué de la visibilidad e invisibilidad de determinadas acciones de RSE. La población de estudio fueron universitarios de 20 a 35 años de la ciudad de Córdoba pertenecientes a estratos medios y medio-altos, quienes evalúan el comportamiento diferentes sectores económicos. La técnica cualitativa empleada fue la reunión de grupos, ocho sesiones de discusión de siete personas cada una, hombres y mujeres. Los participantes construyeron un collage grupal que les evoque el tema en estudio: la responsabilidad social empresaria. El análisis interpretativo consiste en trabajar sobre los collage por medio de una verbalización posterior, luego se describen los rasgos de la personalidad de los sectores, y se procede a efectuar un contraste con la teoría Brands Archetypes y la Teoría de la Disonancia Cognitiva. El estudio muestra la confusión general entre RSE y marketing de causa, la disonancia entre la conciencia responsable y los valores emotivos que despiertan las marcas, la sensación de que muchas de ellas usan la RSE como "pantalla" haciendo invisible las cuestiones sensibles donde los mismos consumidores hacen su "mea culpa" por la falta de conciencia y protagonismo en la temática ética, ecológica y social.

Palabras Clave: RSE; estudio ZMET; consumidores; arquetipos.

\begin{abstract}
This paper aims to investigate the deep emotional perception -conscious and unconsciousof Corporate Social Responsibility (CRS) actions in different economic sectors by the consumers using the ZMET qualitative technique (The Zaltman Metaphor Elicitation Technique), identifying the archetypal brands and their shadows that stigmatize as "negative" or "ambivalent" or "positive" behaviors, in order to create a framework to understand the visibility and invisibility of certain CSR activities. The study population were university students from 20-35 years of Córdoba belonging to middle classes and upper-middle who evaluate the behavior different economic sectors. Qualitative technique used was the meeting of groups, eight sessions of discussion of seven people each, men and women. Participants
\end{abstract}


built a group collage that evokes them the subject under study: corporate social responsibility. The interpretive analysis is to work on the collage by a subsequent verbalization, then the personality traits of the sectors are described, and proceeds to make a contrast with Brands Archetypes and the theory of Cognitive Dissonance. The study shows the general confusion between CSR and cause marketing, dissonance between consciousness responsible and emotional values that awaken the marks, the feeling that many of them use CSR as "screen" making the invisible sensitive issues where the same consumers make their "mea culpa" for the lack of awareness and involvement in ethical, ecological and social issues.

Keywords: CSR; study ZMET; archetypes; responsible and sustainable consumers.

\section{INTRODUCCIÓN}

La problemática ecológica ha sido estudiada por el marketing desde la década de 1970 cuando el problema de la contaminación en las grandes ciudades junto con la posterior crisis petrolera pone en el tapete el tema de la escasez de recursos y obliga al mundo al ahorro de la energía y del petróleo.

Los investigadores de marketing han encontrado en estos temas una línea de investigación iniciada hace ya más de 40 años (Chamorro et al., 2006). Esta ha ido tomando diferentes denominaciones tales como conciencia ambiental, marketing ecológico, verde, eco-marketing, marketing responsable, marketing sostenible, entre otras. Su objetivo ha sido el estudio del impacto de las actividades de marketing en el entorno: en qué medida los consumidores son conscientes, están preocupados o temerosos, qué motivaciones y actitudes asumen frente a la problemática ambiental, cuáles son las acciones que las empresas ejecutan.

En nuestros días, estas temáticas se analizan según el paradigma de la sustentabilidad desde la perspectiva de la Responsabilidad Social Corporativa (RSC), donde las empresas han sabido conjugar sustentabilidad y negocio, haciendo de ello un eje fundamental de su estrategia y su ventaja competitiva, o desde la perspectiva del estudio de las conductas pro-ambientales de las personas, denominada "Consumidor Responsable y Sustentable" (CRS). Adoptamos esta segunda mirada, pues entendemos que son "los consumidores lo que han quedado en un segundo plano, dejando a ellos y a la demanda como elementos pasivos en la ecuación de concientizar y persuadir de adoptar un nuevo sistema de valores” (Havas Media y Fundación Entorno, 2013).

Desde esta perspectiva, el consumidor responsable es aquel que puede realizar un análisis introspectivo de sus hábitos de compra y de sus valores. Es decir que a la hora de decidir la compra de un producto realiza un ejercicio de reflexión sobre diversas cuestiones. En Argentina, el estudio realizado en 2011 sobre la tipologías de consumidores por la RED EDUCA-AL de 
Consumo Responsable y Sustentable (CRS) arroja que solo un tercio se define como tal, es decir como un consumidor consciente y comprometido con el cuidado del ambiente (Almirón et al., 2011). Si bien el concepto de consumo responsable es muy amplio, como lo es la propia actividad de consumir, puede sintetizarse en tres ejes: un Consumo Ético, basado en valores, deliberado, consciente; un Consumo Ecológico, capaz de reciclar, reutilizar, reducir, etc., y un Consumo Social o Solidario, vinculado a las relaciones sociales, laborales y RSC (Iglesias, 2009).

El presente trabajo tiene por objetivo indagar la percepción emotiva profunda -consciente e inconsciente- por parte de los consumidores de las acciones de Responsabilidad Social Empresaria (RSE) de diferentes sectores económicos. Utilizando la técnica cualitativa ZMET (The Zaltman Metaphor Elicitation Technique) ideada por el profesor de marketing de la Universidad de Harvard, Gerard Zaltman, se pretende identificar las marcas arquetípicas y su sombras que los consumidores estigmatizan como conductas "positivas" "negativas" o "ambivalentes", validando un conjunto de arquetipos con el fin de crear un marco de análisis para comprender el porqué de la visibilidad e invisibilidad de determinadas acciones de RSE.

En primer lugar, se presenta la perspectiva de la Responsabilidad Social Empresaria (RSE) y del Consumo Responsable Sustentable (CRS) bajo el paradigma de la sustentabilidad; seguidamente, detallamos la metodología utilizada y el marco teórico referencial de análisis - la Teoría de Disonancia Cognitiva de Festingery el Modelo de Brand Arquetypes de Millard Brown España; posteriormente, a partir de la obtención de los datos como del tratamiento de la información recolectada se destacan los principales hallazgos de la investigación, para finalmente concluir con una serie de reflexiones finales, con las correspondientes implicancias para las empresas.

\section{LA RESPONSABILIDAD SOCIAL DE LAS EMPRESAS Y EL CONSUMIDOR RESPONSABLE Y SUSTENTABLE}

Bajo la filosofía de Responsabilidad Social Empresaria (RSE) se defiende que la creación de valor para los distintos grupos de interés que concurren en la actividad empresarial (stakeholders), redunda en una mayor creación de valor para la sociedad (Fundación Ecología y Desarrollo, 2003). En el contexto de la empresa, el desarrollo sostenible implica un enfoque basado en la triple cuenta de resultados de modo que los beneficios de la empresa no se midan teniendo en cuenta exclusivamente su rentabilidad financiera, sino también en rentabilidad social y medioambiental. La finalidad de las Líneas Directrices para Empresas Multinacionales de la OCDE, publicadas en el año 2000, es promover la cooperación de las multinacionales al desarrollo sostenible, así como fomentar las actuaciones responsables de estas empresas en las comunidades en las que operan. El Global Reporting Initiative (GRI), 
acuerdo internacional puesto en marcha en 1997, en colaboración con el Programa de Naciones Unidas para el Medio Ambiente (PNUMA), promueve la elaboración de Memorias de Sostenibilidad aplicables globalmente y para su uso voluntario por parte de las organizaciones. En este sentido, la Responsabilidad Social Corporativa se puede definir como "el reconocimiento e integración en sus operaciones por parte de las empresas, de las preocupaciones sociales y medioambientales, dando lugar a prácticas empresariales que satisfagan dichas preocupaciones y configuren sus relaciones con sus interlocutores" (De la Cuesta y Valor, 2003). En ese sentido, el Instituto Argentino de Responsabilidad Social (IARSE) y el Instituto ETHOS, trabajan en la creación de herramientas de planificación, estrategia y monitoreo del desempeño de las empresas en siete grandes temas o dimensiones: valores, transparencia y gobernabilidad; público interno; medio ambiente; proveedores; consumidores y clientes; comunidad en general; y gobierno y sociedad. En lo que respecta a los consumidores, los indicadores del IARSE-Ethos apuntalan la idea de dos cuestiones fundamentales: el respeto de los derechos del consumidor y una estrategia de comunicación responsable para el consumo consciente. Se espera que la empresa desarrolle con sus asociados productos y soluciones que reducen el impacto ambiental que provocan y facilitan el re-uso y el reciclaje, promueva acciones educativas para un consumo consciente - mencionando los impactos sociales, ambientales y económicos relacionados a las preferencias del consumidor, ofrezca servicios de recolección y reciclaje de fácil acceso, y divulga abiertamente la composición de precios -impuestos, términos y condiciones de los servicios y productos, incluyendo sus costos de entrega-, promueva la educación para el consumo consciente, lanzando productos más sustentables que conduzcan a un proceso de comunicación capaz de generar cambios efectivos en la selección de productos por parte de los consumidores (IARSE, 2014).

En el mismo sentido, la ISO 26000:2010 destaca en siete asuntos la importancia de que las empresas asuman ciertas responsabilidades con sus consumidores, estas son: 1) prácticas justas de marketing, 2) protección de la salud y la seguridad, 3) consumo sostenible, 4) servicios de atención al cliente, apoyo y resolución de quejas y controversias, 5) protección y privacidad de los datos de los consumidores, 6) acceso a servicios esenciales y 7) educación y toma de conciencia; brindándoles educación e información veraz sobre las estrategias de marketing y contratación, fomentando el consumo responsable y sostenible, y elaborando bienes y prestando servicios que estén al alcance de todas las personas, incluyendo las más vulnerables, entre otras posibles acciones que toda organización debería considerar. También recomienda tener la responsabilidad de retirar productos del mercado que puedan ocasionar daños, y en caso de que se manejen datos privados, asegurarse de que se mantiene la privacidad de los consumidores (ISO 26000, 2010). Lo más importante, se espera que el marketing responsable de las empresas no involucre prácticas que sean confusas, engañosas, fraudulentas o injustas, incluida la omisión de información esencial, ni utilice "imágenes que perpetúen estereotipos en relación con el género, religión, raza, discapacidad o relaciones personales” y que la publi- 
cidad proteja los intereses de los sectores vulnerables como los niños.

Señalábamos que desde la perspectiva del consumidor se sostiene que este es capaz de realizar un análisis introspectivo de sus hábitos de compra y de sus valores a la hora de decidir la compra de un producto, un ejercicio de reflexión sobre diversas cuestiones, como por ejemplo: ¿Necesito lo que voy a comprar? ¿Quiero satisfacer un deseo? ¿Estoy eligiendo libremente o es una compra compulsiva?, entre otras. Las posibles respuestas a esta reflexión dependerá de la perspectiva teórica desde donde se la conteste, la neoliberal, la de la dependencia, la del poder del consumidor y por último, la de la ciudadanía del consumidor (Almirón et al., 2011 en base a Adela Cortina).

Ballesteros (2011) señala que la persona con un comportamiento responsable de consumo pone su acento en su bienestar moral, trata de solucionar situaciones muy claras de disonancia entre lo que se espera de una persona y lo que realmente le apetece. Quizás esto pueda explicarse, una vez más, a través de la coherencia entre lo que uno piensa y como actúa. No es sino desde los valores y creencias firmemente asentados en un individuo desde donde se pueden plantear modelos de consumo y estilos de vida acordes con sus ideas y que no le provoquen infelicidad. Así, el consumo sería la expresión más acabada de la democracia económica y de la autonomía personal, ya que el consumidor vota con cada compra”. Tres ejes centrales que hacen al consumo responsable, a saber:

- Consumo Ético: basado en valores; consumo consciente, deliberado, austero. El consumidor decide ponderando varias variables como precio, conveniencia y factores sociales. Se opone al consumismo como forma de alcanzar el bienestar y la felicidad.

- Consumo Ecológico: Reducir, Reutilizar y Reciclar. Implica una toma de conciencia y respeto por el medioambiente y la comunidad en su conjunto, en la búsqueda del desarrollo sustentable para las generaciones futuras.

- Consumo Social o Solidario: aborda el consumo en lo que refiere a las relaciones sociales y condiciones laborales en las que se ha elaborado un producto o producido un servicio, considerando la responsabilidad social que tienen las empresas. Se trata tener en cuenta "pagar lo justo por el trabajo realizado"; de eliminar la discriminación de cualquier origen; de potenciar alternativas sociales y de integración.

Sin embargo, nos encontramos inmersos en una sociedad consumista caracterizada como aquella en la que las personas consumen bienes fundamentalmente superfluos. Adela Cortina (2003) caracteriza esta época, como una sociedad en la que se consume no lo necesario para la vida sino lo superfluo, y en la que además el consumo legitima la política y legitima la economía; la política se legitima si los políticos son capaces de conseguir un crecimiento económico, mientras que la economía se legitima si cada vez se fabrican productos más sofisticados.

Es posible encontrar numerosos abordajes al concepto de consumo responsable como "consumo y consumidor responsable, crítico, ético, político, consciente y transformador, ciudadano de mercado, etc., y aunque no existe unanimidad dentro de la comunidad cientí- 
fica sobre su significado, todas estas denominaciones vienen a abrazar un concepto de consumo que va más allá del acto dirigido a la mera satisfacción de unos intereses o necesidades individuales" (DÍAZ, 2011).

\section{LA METODOLOGÍA DEL ESTUDIO}

Se llevo a cabo un estudio exploratorio de naturaleza cualitativa, cuya técnica y población de estudio, dinámica desarrollada e interpretación cualitativa se explicitan en los apartados siguientes. La selección de la técnica cualitativa obedece a la poca importancia que se le da dentro de las marketing y la comunicación, en muchos casos, a los estudios de tipo cualitativo que entre otras permiten: a) detectar "insight" y percepciones de los consumidores, en este caso frente a la RSE, b) conocer como decodifican los mensajes comunicacionales de las acciones de RSE emprendidas, c) generar conclusiones que permitan corregir problemas de posicionamiento, imagen y comunicación de las prácticas llevadas a cabo desde RSE y d) proporcionar información sobre el imaginario de los consumidores respecto de que esperan de las empresas.

\subsection{TÉCNICA Y POBLACIÓN DE ESTUDIO}

La técnica utilizada es la Reunión de Grupos o de Discusión. Las razones de esta técnica es pues deseábamos ver la interacción de dos niveles: individual y grupal. La población de estudio son los jóvenes universitarios de 20 a 35 años de la ciudad de Córdoba pertenecientes a estratos medios y medio-altos, quienes evalúan el comportamiento de los sectores petroleros, químicos, alimentos y bebidas, automotor, banca y seguros, y tecnológico. El criterio de selección de estas actividades se funda en un trabajo previo de los autores titulado "El consumidor cordobés y el impacto de las acciones de RSE sobre sus procesos de compra” (Anexo I). Se efectuaron ocho sesiones de grupos de discusión de siete personas cada una, hombres y mujeres en durante los meses de septiembre y octubre de 2013. Los participantes fueron seleccionados de modo no probabilístico sin ningún tipo de condicionamiento, conformado por personas con diferentes grados de conocimiento sobre la responsabilidad social empresaria y de marketing de causa y con diferentes experiencias en temas de voluntariado social derivada de sus prácticas en el nivel medio.

\subsection{DINÁMICA DESARROLLADA}

En la dinámica desarrollada, se les solicita a los participantes que construyan un collage grupal, donde primero, cada individuo recopila imágenes (de revistas, diarios, internet, publicidades, etc.) o que realicen dibujos que de alguna forma, aunque no la comprendan, les evoque el 
tema en estudio: la responsabilidad social empresaria por parte de las empresas del sector desde su perspectiva de consumidores. Se les enumeró previamente las actividades productivas que se incluyen cada sector. Por ejemplo, el sector químico incluye productos de limpieza, perfumería. Segundo, cada entrevistado debía seleccionar entre 8 y 12 imágenes y reflexionar libremente acerca de ellas anotando las razones por las cuales son elegidas. Tercero, el grupo se reúne para armar un collage que represente la imagen del sector, que sintetiza la idea general que lo interpreta mejor y eligen una serie de adjetivos descriptivos "positivos" y "negativos" que mejor expresen para cada uno, la manera en que perciben a estos sectores. Por último, cada grupo es entrevistado con el objetivo que explicite e interprete el sentido de lo que han construido, de modo que puedan estructurar un discurso unificante o explicativo de lo que desean expresar (Datavoz, 2005). El material de base que dispusieron fueron de una cantidad significativa de diarios y revistas de hasta dos años de antigüedad de diferentes temáticas generales, sociales, culturales y de entretenimiento aportados por los investigadores más las que ellos mismo seleccionaron de sus hogares, de modo de evitar que se produzca un sesgo o condicionamiento por parte del material analizado. Cabe aclarar que en ningún momento se les mencionó marcas específicas o ejemplo alguno, tanto de buen o mal comportamiento social por parte de estas, siendo las empresas o marcas aquí descriptas expresiones espontáneas mencionadas por los participantes a partir de su propia experiencia como consumidor o evocadas por ellos del discurso social imperante en el contexto social y cultural que ellos están inmersos.

\subsection{ANALISIS E INTERPRETACION CUALITATIVA}

El análisis cualitativo pretende pasar del polo descriptivo al explicativo en tres fases: análisis de contenido, estructural, e interpretativo. El análisis de contenido se centró en la recolección de la información, la reducción de los datos y la posterior transformación de los mismos, que pasan de un discurso libre y espontáneo a convertirse en un texto con sentido. En el plano del análisis estructural, que implica pasar de un material explícito a un material implícito, de las estructuras manifiestas a las latentes, diferenciándolos diferentes planos de las manifestaciones vertidas: mental, emocional, del deseo y de la acción. Por último, el análisis interpretativo se procede a efectuar por medio de un contraste con la teoría Brands Archetypes y de la Disonancia Cognitiva para definir el/los perfil/es que mejor representan los sectores y las marcas identificadas (Martínez, 2008).

\subsection{BRANDS ARCHETYPES Y DISONANCIA CONGNITIVA}

Los arquetipos simbolizan relaciones básicas del ser humano con el entorno que lo rodea. Carl Gustav Jung desarrolló el concepto de inconsciente colectivo, mediante el cual se refería a la existencia de un lenguaje común a todos los seres humanos, de todos los tiempos 
y lugares (Martínez, 2008).

El término "arquetipo" proviene de las palabras griegas "arje" que expresa la fuente, el principio, el origen y el "typos" o sea la impresión, modelo de representación. Son símbolos que representan relaciones especialmente significativas para el ser humano. Por ejemplo, el héroe es el modelo del arquetipo del valor y del coraje.

Los arquetipos son referentes universales, es decir, íconos consistentes a través del espacio (diferentes países y valores) y del tiempo (distintas épocas históricas). Los arquetipos tienen una sombra que es la versión negativa del mismo. Los grandes mitos, leyendas, cuentos, obras literarias, películas cinematográficas, muestran personajes arquetípicos que remueven a la audiencia porque la conectan con la parte más profunda de su psiquismo. Fue Carlo Jung desarrolló el concepto de inconsciente colectivo, mediante el cual se refería a la existencia de un lenguaje común a todos los seres. El modelo de los "Brands Archetypes" desarrollado por Millward Brown España se muestra en la Tabla 1. Cada arquetipo y cada sombre tienen símbolos, palabras, objetos que lo definen y caracterizan. Por ejemplo, el "Rey" es representado por el Dios, el león, el cetro, el color dorado; significa la fuerza, la potencia, el poder, la autoridad, el orden y el liderazgo. La Sombra es el "Tirano" caricaturizado por el Diablo, Saturno, el tridente, el color negro; representa el déspota, el egoísmo, la prepotencia, la soberbia.

Tabla 1. Arquetipos y sus sombras

\begin{tabular}{|ll|ll|}
\hline \multicolumn{2}{|c|}{ Arquetipos } & \multicolumn{2}{l|}{ Sombras } \\
\hline 1. & El Rey & 1. & El tirano \\
\hline 2. & El sabio & 2. & El charlatán \\
\hline 3. & El héroe & 3. & El villano \\
\hline 4. & El rebelde & 4. & El anarquista \\
\hline 5. & La seductora & 5. & La vampiresa \\
\hline 6. & El comediante & 6. & El loco \\
\hline 7. & El soñador & 7. & El fantasioso \\
\hline 8. & La princesa & 8. & La bruja \\
\hline 9. & El amigo & 9. & El traidor \\
\hline 10. & La madre & 10. & La madrastra \\
\hline
\end{tabular}

Fuente: Elaboración propia.

Por otra parte, en el análisis de la mirada de los sectores económicos, hacemos uso de la Teoría de la Disonancia Cognitiva de Festinger (1957), pero aplicada a las decisiones previas que tienen que tomar los consumidores sobre comprar o no comprar o utilizar servicios de sectores con elevado grado de disonancia. Esta teoría sostiene que ante una decisión, nos encontramos con dos fuerzas, una tensión que percibe una persona al mantener al mismo tiempo dos pensamientos que están en conflicto. Un vector de fuerzas con valencia "positiva" donde el consumidor se ve atraído y no dispuesto a prescindir de él, y por el otro, un vector de fuerza "negativa” dado por los aspectos no responsables en términos éticos, ecológicos o sociales. El conflicto se dirime en la medida que un elemento se elimina o reduce y el otro se potencie, de modo 
de reducir la disonancia psicológica que se encuentra entre estas dos fuerzas opuestas y que le generan un conflicto al consumidor. La teoría de la disonancia cognitiva afirma que la persona se ve automáticamente motivada a reducir dicha tensión hasta conseguir que el conjunto de sus ideas y actitudes encajen entre sí, constituyendo una cierta coherencia interna (Festinger, 1957).

Bajo la mirada de esta teoría, podemos hipotetizar que las acciones de RSE pretenden por un lado o disminuir el peso de un polo - valencia "negativa" o aumentar la valencia "positiva" a fin de que el consumidor de una u otra manera, adquiera mayor conciencia del "daño" o mayor "responsabilidad social" de sus actos de consumo y produzca en él, un cambio en su nivel de conciencia, en su actitud luego y por último, un cambio de conducta, es decir un cambio primero a nivel de conocimiento, seguido de un cambio de preferencia afectiva y luego de elección o comportamiento.

\section{DISCUSIÓN DE LOS RESULTADOS}

Creemos conveniente presentar estos resultados y las implicancias encontradas fruto del estudio a partir de tres preguntas centrales:

1) ¿Cuál es la mirada de los sectores económicos por parte de los consumidores y el grado de disonancia que les producen a partir del paradigma de la responsabilidad social empresaria y de la sustentabilidad?

2) ¿Cómo los consumidores decodifican sus mensajes - promesas de marca y las "mentiras" o "engaños" - en términos de imaginarios arquetípicos y sus sombras?

3) ¿Qué esperan los consumidores de la RSE como contribución en términos del modo de resolución de la disonancia que se les plantea a la hora de consumir o volver a elegir o no la marca?

\subsection{LA DISONANCIA COGNITIVA PARA EL CONSUMIDOR}

Los mensajes y la comunicación de las empresas de los sectores económicos estudiados generan una serie de sensaciones contradictorias en los consumidores cuando se les plantea analizarlo desde la perspectiva de la Responsabilidad Social Empresarial (RSE) bajo el paradigma de la sustentabilidad.

Describiremos a continuación cómo se ven los sectores definidos a partir del análisis del collage efectuado, luego de una revisión crítica y extensa de las entrevistas realizadas. Presentamos en la Tabla 2, la Disonancia Cognitiva para el consumidor rescatando lo "positivo" y lo "negativo" en la percepción de cada sector. En términos generales, se denota de las transcripciones y análisis efectuados que las personas al evaluar cada uno de los sectores señalan tanto sus expectativas, deseos, insatisfacciones actuales, beneficios buscados como las promesas 
formuladas a partir de los mensajes de campañas, programas de marketing de causa, y acciones de responsabilidad social emprendidas por las industrias. Pasamos a analizar cada uno de los sectores que conformaron este estudio, dejando entre comillas, las frases que señalan manifestaciones textuales de los participantes.

\subsubsection{El sector financiero}

Rescatan los participantes del sector financiero - bancos y tarjetas de crédito - en lo positivo lo siguiente: a) la accesibilidad - "utilizadas en todo el mundo", b) la seguridad - "una medida de seguridad" b) el ahorro - "se pueden ganar intereses", c) la tecnología al servicio del ambiente - "menos uso de papel, gracias al home banking", d) su función básica de financiar "créditos a emprendimientos", "pago en cuotas", "más préstamos a empresas", d) sus acciones solidarias - ejemplo "Bancor solidario".

Desde lo negativo se destacan críticas recurrentes en el sector desde hace muchos años como: a) altos costos - "cargos no reconocidos", "cobran las comisiones por uso de cuenta”, "gastos de mantenimiento", b) insatisfacción con el servicio - "demoras en la atención al cliente", c) lo usurario de las tasas de interés - "alta tasa de interés, al momento de pedir un préstamo". Además señalan que el sistema muchas veces es "imprudente" y "exacerba el consumo" pues "incita al gasto más allá de las posibilidades" de cada uno, "incitan en el consumo masivo... insisten en que gastemos cada vez más" pidiendo prestado, más "de lo que podríamos gastar". Las campañas o son engañosas o apelan a la pertenencia a determinados estereotipos de vida, bajo la solapada amenaza de quedar excluido o de la pérdida de "status social": "la tarjeta que todos podrían tener", no te podes negar. Queremos aclarar que mucho de lo negativo se asocia al sector, y no a una empresa en particular, se crítica al sector. Aparecen otras expresiones tales como: "paraísos fiscales", "fuga de capitales", "endeudamiento social”, "dificultad de acceso al crédito", "crisis financieras", "dependencias de las tarjetas" y "publicidad engañosa de tasas". Para el segmento etario estudiado la referencia de "crisis" aparece pero no ligada a los hechos recientes de 2001, sino como escenario del contexto actual mundial pos crisis internacional de 2008.

\subsubsection{El sector seguro}

El seguro es el sector menos conocido por el segmento estudiado salvo por las experiencias vinculadas al seguro automotor. Como "pros" podemos mencionar expresiones ligadas a las necesidades de "seguridad", "confianza" que permiten a los usuarios cierta "evasión de riesgos" o de "situaciones de conflicto y peligro" representados en las imágenes seleccionadas como de "superhéroes", "salvavidas" y familias nucleares constituidas sobre la base del afecto.

Como "contras", los participantes expresan sus sentires y pesares respecto del sentirse "engañados" al momento donde las empresas deben hacer frente a los siniestros: manifiestan los “incumplimientos de promesas", los "pagos demorados”. Otras imágenes gráficas seleccionadas muestran "choques", "robos" y "una casa que se incendia”, esas que nunca muestran las 
publicidades y que al devenir en realidad, expresan las contingencias posibles y concretas que algunos seguros no respaldan. Existe un halo negativo donde se percibe al sector como un negocio bien cerradito y armado que embolsa su dinero -"engaño en los contratos", "letra chica tramposa"- construido el motivo de compra sobre la apelación más al "miedo a” que sobre la "seguridad efectiva".

\subsubsection{El sector petroquímico}

El segmento estudiado se lo asocia a la posibilidad de "libertad de movimiento", de "viajar, moverse". Auto y combustible aparecen asociados. Esta industria simbolizada por el "pozo petrolero" y "el martillo extractor" en movimiento, evocan el dinamismo productivo, el crecimiento del país y manifiestan que es un símbolo del progreso y del trabajo. Esta imagen aparece en el caso argentino muy ligado a la empresa YPF. Por otro parte destacan que los progresos técnicos de la industria petroquímica ha logrado "nuevos materiales", "nuevos bienes más livianos" hoy disponibles en todos los hogares.

Constataron que muchas veces esta industria es el foco de ataque de los grupos ambientalistas que alertan sobre los daños de los "derrames de petróleos", el uso de una fuente de "energía no renovable” y sus efectos contaminantes sobre ríos y mares. Son conscientes que el petróleo es un tema estratégico de los países, una cuestión de "poder de los países", un "negocios de pocos" en referencias a los países árabes, que genera "altos costos" en la economía.

\subsubsection{El sector químico}

El sector químico, en especial la perfumería, la cosmética y los medicamentos tienen un "halo" protector, de arquetipo de madre que cuida. Las expresiones que lo avalan y que aparecen en el discurso publicitario son: "repara y protege", "nutre", "salud” "higiene" "pureza" “cuidado de cuerpo", "belleza”. Por el lado de lo "negativo" emergen conceptos ligados a productos de alto daño para el ambiente como "aerosoles", "producto no biodegradables", productos del agro de "alta toxicidad”. Saben que la industria es capaz de manipular lo natural para crear cualquier tipo de novedad artificial, pero no saben identificar ejemplos concretos. Las marcas aparecen como reaseguro ante el poder de la química en la transformación del mundo que los rodea.

\subsubsection{El sector tecnológico}

El sector tecnológico aparece asociado con la gran revolución en materia de comunicaciones, informática y entretenimientos, siendo él que más conocen. Los aspectos positivos que destacan es el lanzamiento de productos que puedan "facilitar sus tareas", "incrementar las comunicaciones" o "achicar distancias" con otros, lograr mayor "productividad" del trabajo, "pasar el tiempo" más entretenido, lograr más "rapidez” con sus PC. Los aspectos negativos se vinculan con el uso y abuso: "el no hacer actividad física", "vicio" y "stress" de los jueguitos. Añaden que ven la industria como generadora de "una sicosis de la necesidad", de "tener lo 
último" sea para ver, grabar, mirar, chatear, hablar, etc. Los adelantos implican también "control" una "aceleración de todo", un símbolo de mayor "poder" alcanzado. Respecto del impacto en el medio ambiente señalan críticas al no hacerse cargo de las empresas de la "basura tecnológica", la contaminación de sus componentes como las baterías, y la guerra por los "nuevos materiales" que genera un alta competencia y la rapidez de los cambios.

\subsubsection{El sector automotor}

El sector automotor como el tecnológico, es uno de los más cautivantes para el segmento estudiado, sobre todo, al sexo masculino. La mirada destaca ser una "rueda" que hace que las otras industrias "se muevan". Desde "lo positivo" se destaca la "variedad de modelos, colores y gamas alternativas", algunos más "ecológicos que otros". Consideran que la afirmación que "el futuro será verde o no será” es un compromiso de algunas empresas del sector. Creen que la preocupación por el medio ambiente es una de las actividades de RSE preferidas de la industria. Expresan connotaciones positivas tales como: "me muevo" significando expresión de libertad, "diseño atrapa" y "expresa mi personalidad" que hace a la juventud e identificación, "confort" para decir novedad, "aspiracional" como meta de lo querible y deseable, "poder" y "éxito" como representación ante los otros. Destacan el caso del auto eléctrico e hibrido como ejemplos de modernos, ecológicos y como "destino" de donde estas empresas quieren y deben llegar en el largo plazo.

En la mirada de los "oscuro" u "oculto", ubican a los desechos y a la contaminación que generan en su proceso productivo, la gran cantidad de residuos y gases emanados por su uso, que daña la capa de ozono, y en menor medida, el "ruido" que generan en las ciudades. Son conscientes que determinados modelos y marcas juegan con la "ostentación", generando "exclusión” y “diferenciación” muchas veces en exceso. A pesar de ello, la mirada del sector es permisiva frente a todo lo mucho por hacer aún. La demora en el lanzamiento de auto-eléctricos a base de energía solar o combustibles no contaminantes se explica para la mayoría por las presiones de las corporaciones petroleras y no de las automotrices.

\subsubsection{El sector indumentaria}

La vestimenta y la moda especialmente en el sector textil, cautiva más la atención del sexo femenino, pues la forma de vestir "expresa la persona” y el ser femenino. Cada estilo de vida, incluidos los estilos tradicionales de determinadas culturas, se ven hoy reflejadas en ella: hay una especie de democratización del vestir a partir de la moda misma, reconocen los consumidores. Por otro lado, en la sociedad posmoderna diríamos que la "marca, te marca", dice todo de quien la porta, "dice quien sos" y "nos hace sentir hermoso" manifiestan. Por ello, expresa un modelo de belleza que se impone desde la industria textil y cosmética. En el segmento, el "diseño innovador" captura la atención al igual que la “moda”, que además de posibilitar la identificación, expresa el sentido de "pertenencia” 
a grupos y subculturas urbanas diversas.

Las consecuencias del alcance actual del fenómeno de la moda, lleva a una serie de "trastornos" que hoy no son tabúes y son reconocidos, como la "bulimia" y "anorexia": imágenes de mujeres demasiado delgadas sumado a los pequeños talles que esta impone, lleva a graves trastornos de alimentación sobre todo en adolescentes, que siendo conscientes del fenómeno, no lo pueden evitar o controlar. Abiertamente expresan que el arquetipo de mujer "barbies" se observa en los desfiles y pasarelas, y que al no lograrlo, muchas se frustran. Los escándalos mediáticos han puesto en tapete otras cuestiones, antes no visibles, pero tan serias como las mencionadas anteriormente que son: la "discriminación", el "trabajo infantil" y esclavo, y en menor medida el tema del "uso de pieles" y la "explotación de animales".

\subsubsection{El sector alimenticio}

Los consumidores identifican rápidamente una empresa estereotipada por los medios y por las críticas recibidas por especialistas en materia de nutrición infantil del mundo entero. Se trata de la imagen de la firma McDonald's, representada por los sectores críticos como una “fábrica de obesos". Señalan tener dificultades a la hora identificar conductas responsables de la empresas en orden a la falta de claridad de la información que brindan. Apuntan en forma reiterada, que hay una gran confusión que impide comprender las denominaciones o etiquetas como "diet”, "light”, “cero calorías", "reducido" en las categorías de aguas saborizadas, gaseosas y jugos, entre otras. Además, en las etiquetas se perciben una falta de criterios claros y muchas contradicciones en las denominaciones de los productos - alimentos transgénicos versus orgánicos versus naturales. Visualizan que los empaques aún necesitan mejorar y que son poco eco-sustentables y que proliferan aún demasiados envases plásticos. Dicen reconocer mucha información redundante que termina repercutiendo en un serio problema de credibilidad tanto de las acciones de RSE o como del marketing responsable. Para los jóvenes, existe publicidad engañosa - demasiadas "mentiras piadosas" en categorías como bebidas sin alcohol, comidas rápidas, productos de origen lácteo (alimentos "funcionales") como Activia, Actimel y Danonino. En síntesis, visualizan una manipulación de la industria alimenticia de los productos naturales que ya "no son como eran antes" y que no necesariamente, significan que sean mejores: muchos aditivos, muchos colorantes y conservantes que alteran la esencia del producto "natural”. En este sentido la autoridad de aplicación pareciera permitirles a estas, este tipo de políticas poco transparente.

Por otra parte, destacan una serie de imágenes positivas que comprenden dibujos de la naturaleza, alimentos sanos, alimentos "placenteros", símbolo de reciclaje, frases sobre cuidar para las generaciones futuras. Reconocen que hay empresas que se toman en serio la meta de ofrecer "comida sana”, apoyan el reciclado y reutilización de envases y que están trabajando en el desarrollo de nuevos productos para enfrentar la demanda mundial de alimentos, pero no 
son capaces de nombrar una marca en especial. A pesar de la imagen crítica respecto de McDonalds, rescatan como positivo, la campaña efectuada con motivo de los Juegos Olímpicos 2012 para que las personas coman menos calorías. Si bien son temerosos respectos de las bondades de los alimentos transgénicos, lo reconocen como "positivo" debido a los avances para aplacar el hambre en el mundo.

Tabla 2. Claves de la Disonancia Cognitiva para el consumidor

\begin{tabular}{|c|c|c|}
\hline Sector & Positivo & Negativo \\
\hline Financiero & $\begin{array}{l}\text { "seguridad" "accesibilidad" "disponibilidad" } \\
\text { "utilizadas en todo el mundo" } \\
\text { "menos uso de papel - home banking" } \\
\text { "créditos a emprendimientos" "pago en cuotas" } \\
\text { "más préstamos a empresas" "Bancos solidarios" }\end{array}$ & $\begin{array}{l}\text { "intereses excesivos" "gastos de comisión" } \\
\text { "altos costos y tasas" "tentación para seguir } \\
\text { comprando" "paraísos fiscales" } \\
\text { "publicidad engañosa de tasas" “endeudamiento } \\
\text { social" "dificultad de acceso al crédito" "crisis } \\
\text { financieras" "dependencias de las tarjetas" }\end{array}$ \\
\hline Seguros & $\begin{array}{l}\text { "evadir los peligros" "seguridad" } \\
\text { "vida despreocupada" “inversión valiosa" } \\
\text { "signo de bien-estar" "evita sufrir" }\end{array}$ & $\begin{array}{l}\text { "engaño en los contratos" "letra chica tramposa" } \\
\text { "hechos que no cubren" "burócratas" }\end{array}$ \\
\hline Petroleras & $\begin{array}{c}\text { "libertad de movimiento" "viajar, moverse" } \\
\text { "nuevos bienes más livianos" }\end{array}$ & $\begin{array}{l}\text { "derrame de petróleo" "poder de países" "negocios } \\
\text { de pocos" "altos costos" "energía no renovable" }\end{array}$ \\
\hline Químico & $\begin{array}{l}\text { "salud" "higiene" "pureza" " } \\
\text { cuidado de cuerpo" "belleza" }\end{array}$ & $\begin{array}{l}\text { "aerosoles" “ exceso de tóxicas" "daño capa de ozono" } \\
\text { "no biodegradables" "manipulan natural" "artificial" }\end{array}$ \\
\hline Tecnológico & $\begin{array}{l}\text { "facilita tareas" "comunicar con otros" } \\
\text { "achica distancias" "productividad" } \\
\text { "pasar el tiempo" "rapidez" }\end{array}$ & $\begin{array}{l}\text { "stress" “vicio" "quita tiempo para actividad física" } \\
\text { "tensión" "tener lo último" }\end{array}$ \\
\hline Automotor & $\begin{array}{c}\text { "me muevo" "diseño atrapa" } \\
\text { "expresa mi personalidad" } \\
\text { "confort", "aspiracional" “poder" “éxito" }\end{array}$ & $\begin{array}{l}\text { "contamina aire" "ruido" “CO2" "daña capa ozono" } \\
\text { "ostentación" "exclusión" "diferencia" }\end{array}$ \\
\hline Textil & $\begin{array}{l}\text { "expresa la persona" "marca, te marca" } \\
\text { "dice quien sos" "diseño innovador" } \\
\text { "moda" "pertenencia" }\end{array}$ & $\begin{array}{l}\text { "trastorno" "bulimia" " anorexia" "trabajo infantil" } \\
\text { "discriminación" "explotación de animales" }\end{array}$ \\
\hline Alimentos & $\begin{array}{l}\text { "saludables" "sanos" "nutritivos" } \\
\text { "reciclan envases" }\end{array}$ & $\begin{array}{l}\text { "comida rápida" "exceso" } \\
\text { "obesidad" "transgénicos" }\end{array}$ \\
\hline
\end{tabular}

Fuente: Elaboración propia a partir del Modelo de Brands Arqueypes. Martínez, Pepe (2008) 


\subsection{LA MIRADA ARQUETÍPICA Y SU SOMBRA}

La construcción del imaginario arquetípico de los sectores que presentamos en la Tabla 3, la mirada de los consumidores de cada sector en términos de arquetipos y sombras que aparecen de manera espontánea en el relato de las marcas nombradas y de los ejemplos citados, sintetizados y descriptos en el apartado anterior.

Tabla 3. ARQUETIPOS Y SOMBRAS

\begin{tabular}{|l|c|c|}
\hline \multicolumn{1}{|c|}{ Sector } & Arquetipos & Sombras \\
\hline Bancos y Tarjetas & $\begin{array}{c}\text { Héroes } \\
\text { Amigos } \\
\text { Sabios }\end{array}$ & $\begin{array}{c}\text { Traidores } \\
\text { Charlatanes }\end{array}$ \\
\hline Seguros & $\begin{array}{c}\text { Seductores } \\
\text { Reyes }\end{array}$ & $\begin{array}{c}\text { Vampiros } \\
\text { Traidores }\end{array}$ \\
\hline Petroleras & Seductor & Charlatán \\
\hline Químico & Sabio & Vagos \\
\hline Tecnológico & $\begin{array}{c}\text { Creadores } \\
\text { Soñadores }\end{array}$ & $\begin{array}{c}\text { Traidor } \\
\text { Charlatán } \\
\text { Madrastra }\end{array}$ \\
\hline Automotor & $\begin{array}{c}\text { Soñadores } \\
\text { Tiranos }\end{array}$ \\
\hline Textil & $\begin{array}{c}\text { Amigos } \\
\text { Méróros }\end{array}$ \\
\hline
\end{tabular}

Fuente: Elaboración propia a partir del Modelo de Brands Arqueypes. Martínez, Pepe (2008)

En el sector financiero, tres ejemplos claros de marcas arquetípicas fueron identificados: Tarjeta Naranja, Banco Francés y American Express. El primero, asociado al arquetipo "Héroe" ya que representa la confianza en uno mismo, el valor, el coraje, el carisma y el éxito frente a la adversidad, generando en el consumidor un deseo de superación y de identificación. El segundo, relacionado con el arquetipo "Amigo" ya que representa la compañía, la cercanía, el apoyo, la lealtad, la nobleza y la honestidad. El usuario se siente comprendido, confiado y seguro. Ambas dos, suelen ser marcas asociadas como muy fiables. El tercero, la Tarjeta American Express aparece como el "Seductor", aquella que desafía a alcanzar: "la tarjeta que todos podrían tener, la que hace referencia al mundo".

Ante la imagen negativa descripta del sector seguros, las compañías están obligadas a fomentar la confianza de los clientes, convencerlos de que sus inversiones lo valen y que su bienestar es una prioridad para ellas. En este rol podemos reconocer un arquetipo: la "Seduc- 
tora”, que asociamos al posicionamiento que presentan aquellas empresas para "engatusar". Contrasta este con otro discurso que emerge, el arquetipo de "Rey", la empresa líder, en la que la gente invierte con más confianza, la que tiene más prestigio, apareciendo mencionadas firmas tales como: Swiss Medical Group, Zúrich, Sancor Seguros. Bajo el arquetipo del "Traidor" se refugian las connotaciones negativas que se asocian con falta de respuesta en la cotidianeidad e integridad de las empresas. Su aparición se origina en las instancias en las que se pierde la confianza en las promesas frente a la realidad. Se expande a partir de las historias concretas vividas y relatadas por los otros. Ante este escenario, el consumidor es precavido, y siempre tiene presente la posibilidad de "traición", del incumplimiento de las promesas y de la insatisfacción potencial.

Decíamos que en el sector químico, en especial la perfumería, la cosmética y los medicamentos tienen un "halo" protector, de arquetipo de madre que cuida. Las expresiones que lo avalan y que aparecen en el discurso publicitario son: "repara y protege", "nutre", "salud" "higiene" "pureza" "cuidado de cuerpo", "belleza”. La Madrasta aparece como la imagen de la dependencia de las marcas, de los avances que hay que seguir sobretodo el mercado de la cosmética y perfumería. Esta sombra, es decir la mirada oculta negativa que surge de la experiencia proyectiva de los consumidores y está reflejada en: a) las quejas respecto de los "altos costos" de los medicamentos - que a veces lleva a "precios de usura", b) el uso de la química para "creación de armas químicas", c) la contaminación por "sustancia tóxicas" de los procesos industriales, d) la venta de productos que no distinguen si son elaborados sobre base natural o a partir de sustancias sintéticas.

Marcas de tecnología como Sony, LG, Samsung, HP, Apple fascinan al segmento. Apple expresa simbólicamente la figura o arquetipo del creador, refiriéndose a inventor, artista. Es la marca referente del sector, representa la cultura creativa e innovadora para captar constantemente a los clientes. Otra marca reconocida es HP retratada como "el Sabio", el poseedor del conocimiento y de la inteligencia, capaz desarrollar todos los componentes informativos, como la que brinda a las personas, los productos que facilitan las tareas del día a día.

En el sector automotor, cada marca tiene un arquetipo bien definido acorde con el concepto e imaginario que desean transmitir: Toyota, la marca "fiable" en todas sus gamas; Audi, es el líder el "Rey”; Fiat, es la marca "Soñadora”, proyecto de futuro; BMV, es la joya, el premio, la conquistar "inaccesible", una especie de "la Princesa" de sus sueños.

En alimentos, muchas empresas aparecen representadas por el arquetipo Amigo/Padre "bueno" o condescendiente: McDonalds, que es visto como un lugar donde pasar momentos familiares y con amigos, que te alimenta, divierte, líder en el sector de comida rápida, que demuestra calidad y confianza, asociada a otras empresas líderes como Coca Cola. Su sombra es Mentiroso/Astuto, pues en el fondo para algunos no le interesa la salud de las personas, y es percibido como una "fábrica de gordos", o por el uso de packaging contaminante y con poco compromiso con el medio ambiente. Otras marcas construidas bajo el arquetipo del "Héroe" 
son las de la categoría de bebidas saborizadas y las isotónicas - Ser, Powerate, Gatorade, - usadas para rehidratar y recuperar carbohidratos agotados durante el ejercicio, apoyando y promocionando el ejercicio físico y una vida saludable. La "máscara" o la sombra del engaño y la seducción lo constituye su estilo de mensaje publicitario, pues los consumidores son influenciados por imágenes de atletas famosos, bajo mensaje implícito, que expresa que "consumir esta bebida te hará como ellos".

\section{REFLEXIONES FINALES}

Lo que podemos apreciar, a modo de primera síntesis es que las percepciones positiva y negativa se enmarcan en el contexto social y cultural de nuestra época caracterizada por una "cultura del tener", "del ser por el tener", “de la practicidad”, "de una cultura de la comodidad” que los segmentos jóvenes no quieren resignar.

Al fin de cuenta, pareciese que el consumidor joven no cuestiona, ni es demasiado crítico con la lógica del consumo y de la producción vigente pues son parte de ella; es por eso que casi que pareciese que la sostienen y fundamentan, a lo sumo, queda sobrevolando la sensación que más bien se adaptan ante las propuestas de las empresas más que asumir una actitud más pro-activa hacia la cultura descripta. Los jóvenes son más bien reactivos antes las propuestas, sean estas tituladas o no bajo el rótulo de responsabilidad social, marketing de causa o cualquier otra denominación que estas tengan.

$\mathrm{Al}$ analizar el discurso latente, se denota que la generación actual perpetúa los argumentos, pautas de consumo, modelos arquetípicos y estereotipos de identificación, deseos y aspiraciones de las generaciones que los precedieron, que fueron construidas y sostenidas a lo largo del siglo $\mathrm{XX}$. El aporte de este estudio cualitativo pone de relieve a grandes rasgos seis ideas conclusivas en el contexto de toda la investigación que trascienden a lo expresado hasta ahora.

En primer lugar, los consumidores en todos los sectores, pueden visualizar claramente aspectos positivos y negativos percibidos relacionados con la dinámica de cada industria y la práctica de la RSE.

En general, hay una baja capacidad de identificación de las acciones concretas de RSE que las empresas hacen a favor de los consumidores o de la comunidad sea en lo mediato como a futuro, sea porque estas pareciese que no son debidamente comunicadas o lo más importante, no sean sostenibles en el tiempo.

De todas maneras, se revela que existiesen en el imaginario de este grupo, sectores que naturalmente están condenados previamente por la mirada del consumidor, independientemente del perfil de las empresas que lo conforman. En este grupo se destacan las industrias vinculadas con la química, el petróleo y los servicios financieros, sobre todo en relación a su impacto am- 
biental y el manejo poco claro de la información y de las comunicaciones hacia el mercado.

Aún así, dentro de este marco general de posicionamiento que transfiere el sector en el que se ubican las marcas, pueden identificarse compañías con mejor desempeño que otras, que inclusive logran neutralizar los elementos negativos que le son transferidos por la mirada que tiene el consumidor de su industria donde operan.

También, es importante destacar, que en este segmento demográfico, que podríamos ubicar dentro de la reconocida Generación Y, si bien no manejan información clara y precisa sobre las acciones de RSE, los conceptos genéricos de medio ambiente, ecología y responsabilidad social estarían presentes con mayor intensidad y de manera espontánea, en relación a lo que podríamos observar en otros grupos, particularmente de las franjas etarias de adultos y adultos mayores.

Por último, creemos que estas ambivalencias mencionadas, no se traducen necesariamente en un replanteo del comportamiento de consumo, pues el cuestionamiento ético pareciera sucumbir ante la persuasión y seducción de las marcas. Queremos remarcar que estos son conceptos que están instalados y aparecen de manera espontánea, aunque no en todos los casos generan impacto directo en las decisiones de compra de estos consumidores.

\section{REFERENCIAS BIBLIOGRÁFICAS}

Almirón, Z, Bianchi, E; Ferreyra, S \& Kosiak De Gesualdo, G. (2011). Contribuciones al Consumo Responsable, una mirada regional. XXIV Educa-AL. San Juan. Argentina.

Ballesteros, C. (2011). Soberanía consumidora. Más allá del consumo responsable. En ¿Cambiar el Mundo desde el Consumo? Economistas sin Fronteras. DossieresEsF, nº 2, Julio de 2011.

Chamorro Mera, A.; Miranda González, F.J \&Rubio Lacoba, S. (2006). El estado de la investigación sobre marketing ecológico en España: análisis de revistas españolas 1993-2003. Investigaciones Europeas de Dirección y economía de empresas, vol. 12, nº 2, pgs. 137-156.

Data Voz (2005). Los indecisos desnudan a Sebastián Piñera. Estudio desarrollado por DATAVOZ, Chile, Julio de 2005.

Cortina, A. (2002). Por una ética del consumo. Madrid: Taurus.

De la Cuesta, M. Y. Valor, C. (2003). Responsabilidad social de la empresa. Concepto, medición y desarrollo en España. Boletín económico del ICE, n. 2755, 7-19. 
Díaz, E. (2011). Abanico de opciones para ciudadanos responsables. En“¿Cambiar el Mundo desde el Consumo?. Economistas sin Fronteras. DossieresEsF, nº 2, julio de 2011.

Festinger, L. (1957). Teoría de la Disonancia Cognitiva. Madrid: Centro de Estudios constitucionales.

Fundación Ecología y Desarrollo (2003). Anuario sobre Responsabilidad Social Corporativa en España 2003. Recuperado en: www.ecodes.org/responsabilidad-social/ anuario-sobre-responsabilidad-social-corporativa-en-espana-2003\#.VInlgcm4EQI

Havas Media y Fundación Entorno (2010). Crear un nuevo estilo de vida sostenible. Una oportunidad para las marca. Recuperado de www.compromisorse.com/upload/ estudios/ooo/236/Informe_Marcas_y_Comunicacion.pdf

Iarse- Ethos (2014). Indicadores para negocios sustentables y responsables. Programa Latinoamericano de Responsabilidad Social Empresaria. Recuperado de: www.iarse.org/ seccion/wp-content/uploads/2014/o8/Indicadores-Ethos-IARSE-V3.1.compressed.pdf

Iso 26000 (2010). Guía de Responsabilidad Social. Capítulo Asuntos de los consumidores y responsabilidad civil. Recuperado en: www.conseser.com.ar/images/news/iso-260oo.pdf

Martínez, Pepe. (2008). Cualitativamente. Los secretos de la investigación cualitativamente. ESIC. Madrid. España. 2008.

Naciones Unidas (1985). Directrices de las Naciones Unidas para la protección del consumidor (versión ampliada en 1999). Recuperado en: www.consumersinternational.org/ media/33875/consumption_sp.pdf 


\section{ANEXO I}

Estos sectores fueron estudiados en un estudio previo de 2012 titulado "El consumidor cordobés y el impacto de las acciones de RSE sobre sus procesos de compra” (Trabajo no publicado) Los criterios de elección lo definieron un grupo de expertos en función de cuáles sectores de consumo ellos consideraron que eran posibles ser visualizados y evaluados por parte los consumidores a partir de sus experiencias previas. Los sectores elegidos y las preguntas iniciales estimuladoras desarrollados por los expertos fueron:

1. Financiero (Bancos y Tarjetas): ¿Defienden a sus clientes y les protegen sus ahorros e inversiones?, ¿Cobran por sus servicios tarifas e intereses justos?

2. Seguros: ¿Capacitan a sus clientes en prevención?, ¿Dan asistencia correcta a sus clientes ante los siniestros?, ¿Tienen una política clara de defensa de los intereses de sus clientes?

3. Químico: ¿Desarrollan productos al alcance de todos los habitantes?, ¿̇Informan de las contraindicaciones de los medicamentos en forma honesta y veraz? ¿Creen que las publicidades de cosmética y perfumería estimulan estereotipos que exaltan valores o antivalores?

4. Tecnología: ¿la tecnología actual requiere de nuevos minerales y componentes cuyo procesos productivos no comprometen a las generaciones futuras? ¿educan a los consumidores sobre los abusos en el uso de dispositivos (pantallas, tablet, celulares, etc.)?

5. Petroleras: ¿Se responsabilizan de los daños ambientales?, ¿̇Invierten en tecnologías de exploración menos contaminantes?, ¿Auspician investigaciones en tecnologías sustentables no renovables?

6. Automotriz y autopartes: ¿Desarrollan productos en función de las necesidades de las personas?, ¿Son menos contaminantes?, ¿No estimulan deseos aspiracionales en forma excesiva vía el diseño y la publicidad?

7. Indumentaria: ċlas formas de producir no utilizan trabajo infantil o esclavo?, ¿̇la cadena productiva paga salarios justos?, ¿̇se combate la informalidad?, ¿̇la industria de la moda idealiza tendencias inaccesibles y perjudiciales para la salud y el cuerpo?

8. Alimentos y Bebidas: ¿ayudan a los consumidores a cuidar su salud y prevenir enfermedades por mala alimentación o exceso de bebidas?, ¿ayudan a los sectores de menos recursos a contar con una dieta rica y nutritiva a precios accesibles? 


\section{CURRICULUM VITAE}

\section{Enrique Carlos Bianchi}

Doctor en Ciencias Económicas (UNC) y Master en Dirección de Empresas (UCC). Especialización en Marketing en Montpellier-Francia. Profesor titular de Seminario de Investigación de Mercado de UCC y Profesor Titular de FCE de Universidad Nacional de Córdoba en Comercialización y Plan de Marketing y Simulación. Director del proyecto "Responsabilidad social y vínculos de los actores económicos y sociales y el consumidor en las cadenas de valor en pos del desarrollo sustentable" de la Unidad Asociada al Conicet de la UCC.

geomarket@arnet.com.ar

\section{Gaspar Gracia Daponte}

Licenciado en Comercialización de Universidad Siglo XXI. Profesor de Seminario de Investigación de Mercado de la Universidad Católica de Córdoba. Director de la consultora en investigación de mercados Gracia Daponte y Asociados. Maestrando en Dirección de Empresas (UCC). Miembro de equipo de investigación de la Unidad Asociada de Conicet de la UCC.

ggracia@graciadaponte.com.ar 